\title{
Prioritization of Water Resources Management Problems in North Central Nigeria Using Rapid Impact Assessment Matrix (RIAM)
}

\author{
Olayinka Gafar Okeola', Khadijat Abdulkareem Abdul Raheem² \\ ${ }^{1}$ Department of Water Resources and Environmental Engineering, University of Ilorin, Ilorin, Nigeria \\ ${ }^{2}$ Department of Civil Engineering, University of Ilorin, Ilorin, Nigeria \\ Email: drogokeola@gmail.com
}

Received 4 July 2015; accepted 22 March 2016; published 25 March 2016

Copyright @ 2016 by authors and Scientific Research Publishing Inc.

This work is licensed under the Creative Commons Attribution International License (CC BY).

http://creativecommons.org/licenses/by/4.0/

(c) (i) Open Access

\section{Abstract}

This study employed the Rapid Impact Assessment Matrix (RIAM) to prioritize the water resources management problems in the North Central Nigeria. This was done through the assessment of the status of water resources management in the region, evaluation of existing policy and strategy of water management, identification of the management problems and the prioritization with RIAM. The stakeholders identified water resources management problems, ranked them in other of severity in different categories and also evaluated them using the RIAM techniques in the administered questionnaire. Eleven problems were analyzed based on the physical/chemical, biological/ecological, social/cultural and economic/operational factors using several impact indicators. Scores were assigned, the RIAM models applied and the averages taken to arrive at the final assessment scores. The two major water resources management problems identified are: 1) inadequate funds for further agricultural, hydroelectric, navigation and industrial development; 2) poor data collection and banking. These problems were prioritized by RIAM in order of severity for urgent intervention. The RIAM technique has made a key contribution to the prioritization of water resources management by providing insights into urgent problems according to stakeholders and thus guides the policy maker in appropriate decision making.

\section{Keywords}

Water Resources, Rapid Impact Assessment Matrix (RIAM), Stakeholders, Prioritization, North Central Nigeria 


\section{Introduction and Literature Review}

Nigeria is assumed to be endowed with abundant water that cannot be exhausted; however, there are increasing indications that contradict this statement. As the nation's population and socio-economic activities increase so also water pollution, water demand for domestic, agriculture, industry and other usage. Moreover, climate change is making Nigeria increasingly vulnerable to frequent droughts and flash floods with attendant loss of life and property. All these are leading to water crises that need urgent measures to reverse. Besides, the importance of water for socio-economic development is globally recognized since accessibility to adequate water supply is central to life and sustainable development. Nigeria like other sub-Saharan countries loses about 5 percent of its GDP annually as a result of under-development and poor management of water resources. This loss value exceeds the total foreign aid and debt relief inflow into the country [1].

The Federal Ministry of Water Resources (FMWR) is constitutionally empowered to oversee the development and management of Nigeria's surface and groundwater resources including international waters with the following principal functions [2]: formulate appropriate water resources legislation; update and implement the Water Resources Master Plan; formulate and implement national irrigation policy; develop and support irrigated agriculture; coordinate the development and utilization of water resources for irrigation and other purposes; collect, store, analyze and disseminate hydro-meteorological, hydrological and other data among others. The National Water Resources master plan was completed in 1995 with the objective to ensure optimum use of the nation's water resources. It provided for developmental scenario through well formulated strategies in the short and long term by the year 2000 and 2020 respectively. The Water Resources Act (WRA) 2004 vested rights and control of all water, surface and underground including all water-course affecting more than one state on the federal government through the Federal Ministry of Water Resources.

There have been several policies and strategies in the management of water resources in Nigeria which has not translated to the needed social, economic and environmental goals of sustainable development. The current approach to water resources management has been inadequate. This is manifested in 70 million Nigerians without access to potable water supply and food insecurity. 194,000 Nigerian children under the age of 5 die annually due to water borne diseases [1]. Nigeria also lags behind in the sustainable water resources management which affects water dependent sectors. From irrigated agriculture to power generation, industrial and domestic applications, the inefficiency of the resources management are felt. The Federal Government capital expenditure profile on water infrastructure was N782 billion between the year 2000 to 2012 [3] with no corresponding improvement in the sector.

Okeola and Sule, [4] used analytical hierarchy process (AHP) to study the urban water supply scheme in Offa, Kwara State, Nigeria. The Offa water work was studied with the model to assist its future operation and the design of alternative system improvement works. The study introduces three management options that are formulated on the prevailing nation's water supply sector and foreign countries models. The three options are respectively: Public Ownership and Operation; Public Ownership and Private Operation; and Private Ownership and Operation. The result shows that the stakeholders have chosen option 1 i.e. the Public Ownership and Operation as most contributing to sustainable operation of the urban water supply service delivery under scrutiny of environmental, economical, technical, institutional, and socio-cultural criteria. The choice of option 1 reaffirms the stakeholder opinion in the earlier general survey that they did not want government to abandon their responsibility in the water sector. The ranking of the choice is based on the compromise solutions according to the performance of the system under various alternatives that are considered and the preference of the decision makers (DMs) or stakeholders on Performance Indicators (PI) adopted.

Schardong and Simonovic, [5] in their report presented an application of evolutionary algorithms to multiobjective analysis of water resources systems and their integration into a decision support system (DSS) which are the AcquaNet and ModSim which took the advantage of two multi-objective evolutionary algorithms. The algorithms are developed in the form of DSS which enables generalized multi-objective analysis with a focus on water resources systems. The possibilities of application of the developed DSS and multi-objective evolutionary algorithms are initially exploited by multi-objective analysis of a hydrological rainfall-runoff model Smap. The analysis was then extended to a complex water resources system, the Cantareira System that provides water supply for nearly half of the Sao Paulo Metropolitan Region (SPMR) in Brazil. The analysis was done by comparing two pairs of objective functions: minimization of demand deficits versus minimization of pumping cost and minimization of demand deficits versus minimization of the deviation from the water quality standards. The 
results show that the multi-objective evolutionary algorithms are suitable for application to integrated water resources management and represent a good alternative to the "classical" methods. This is because satisfactory results were produced and non-dominated solutions were found without much difficulty. They concluded that DSS developed in this study represent important tools for managers and decision makers for management in complex systems considering multiple uses and explore potential solutions to conflicts arising from water use.

Yilmaz and Harmancioglu [6] applied the water resource management model that facilitates indicator-based decisions, with respect to environmental, social and economic dimensions in a multiple criteria perspective for Gediz River Basin in Turkey. The basic input for the model was the quantity of surface water allocated for irrigation purposes. The model was applied under 3 different hydro-meteorological scenarios that reflect baseline as well as better and worse conditions of water supply and demand. This was not only to reach a comprehensive assessment of the water budget in the Gediz Basin but also to evaluate the impacts of proposed management alternatives under different conditions. The Water Evaluation and Planning (WEAP) software was used as simulation and evaluation tool to assess the performance of possible management alternatives. The study delineated the best management alternatives on the basis of three different multi-criteria decision making methods: simple additive weighting (SAW), compromise programming (CP) and technique for order preference by similarity to ideal solution (TOPSIS). The results show that the decision on best alternative was basically independent of the MCDM method used but slightly sensitive to the weights assigned to the criteria as well as the data used in the analyses. It was established that the developed methodology is a valuable tool for the assessment of water resources systems which illustrates an efficient implementation of an integrated water resources management approach for the basin.

RIAM was successfully used to prioritize water resources management problems in Ghana according to the most urgent attention. The priority list was validated and accepted to be the true reflection of the situation at a national workshop in which experts and representatives from water agencies, donor agencies, university faculties and departments, research institutes, private institutions and organizations including Non-Governmental Organizations (NGOs) participated [7]. The study revealed that RIAM can also be used in a developing country like Ghana and is a very useful tool in prioritization process as applied in the exercise.

This study aimed at reviewing and evaluating the status of water resources management in the north central Nigeria, identifying its challenges and prioritizing them to know which requires the most urgent attention and intervention using the Rapid Impact Assessment Matrix (RIAM). This was done through consultation with stakeholders in the sector with vast experiences and understanding of the resources of the region. The region is important considering the role it plays in the water resources of the country.

\section{Materials and Methods}

The methodology employed in this study involves four main stages which are illustrated in the flowchart (Figure 1). Information and data were collected from government documents and gazettes from water related ministries, agencies and organizations. Information was also obtained through discussions with stakeholders. This information aids the design of the questionnaire which was administered. The data obtained from the questionnaires were reduced to capture the most key information needed for RIAM. Subsequently, the data are subjected to RIAM model (coded in excel 2010) for analysis. The outputs of the model are presented graphically in histograms.

An organized workshop consisting of experts and stakeholders in the field of water resources is required for the study. However due to limited fund and logistics, the use of well-structured questionnaire was adopted for these audience. The questionnaire is purposely designed for the stakeholder group in Table 1. A pilot study was
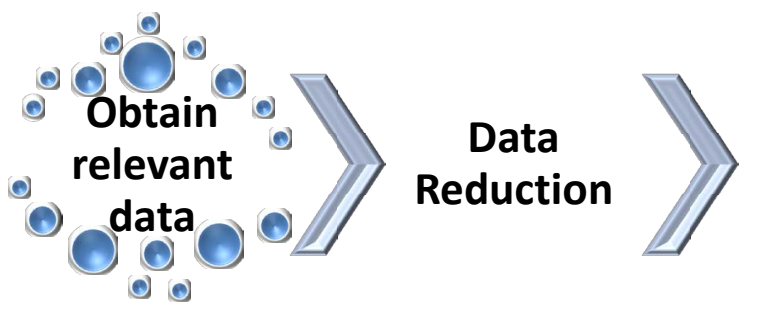

RIAM Analysis

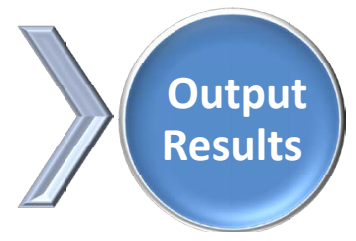

Figure 1. Flow chart showing the stages of the methodology employed. 
Table 1. Stakeholder groups.
(1) Federal Ministry of Water Resources
(2) State Ministries of Water Resources, Agriculture and Environment
(3) State Water Corporations
(4) Lower Niger River Basin Development Authority
(5) Higher institutions
(6) Water industries in the private sector.

first carried out using informal discussions with representatives from the groups. This gave insights on the issues of challenges of management of water resources in their perspectives. Out of the 50 questionnaires that were administered, 34 were completed and retrieved. This is a response rate of $68 \%$. The stakeholders are experts and policy makers in the field of water resources who are spread across different water related organizations in the study area.

In using the RIAM the following assumptions were considered [7]:

1) Water resources management problems are considered to impact negatively.

2) Positive impacts of water resources management issues do not pose any threat and therefore not considered relevant.

3) The importance of a problem could be localized or extensive i.e. affect the immediate environment only or can spread beyond.

The RIAM method is based on a standard definition of the important assessment criteria, as well as the means by which semi-quantitative values for each of these criteria can be collated to provide an accurate and independent score for each condition [8]. The assessment criteria are divided into two categories:

1) Group (A) criteria

Criteria that are of importance to the condition and which can individually change the score obtained.

2) Group (B) criteria

Criteria that are of value to the situation but individually should not be capable of changing the score obtained.

The value of each of these groups of criteria is determined by the use of a series of simple formulae which allow the scores for the individual components to be determined on a defined basis. The values of score in group (A) criteria are multiplied together while those of group (B) criteria are summed up. The final assessment score for the condition is obtain by multiplying the result of group (A) by the result of group (B) indicated in Equations (1), (2) and (3) respectively.

$$
\begin{gathered}
(\mathrm{A} 1) \times(\mathrm{A} 2)=\mathrm{AT} \\
(\mathrm{B} 1)+(\mathrm{B} 2)+(\mathrm{B} 3)=\mathrm{BT} \\
(\mathrm{AT}) \times(\mathrm{BT})=\mathrm{ES}
\end{gathered}
$$

where,

(A1) and (A2) are individual criteria scores that are of importance to the condition (group A) and which can individually change the score obtained. (B1) to (B3) are the individual criteria scores that are of value to the situation (group B) but individually should not be capable of changing the score obtained.

AT is the result of multiplication of all (A) scores;

BT is the result of summation of all (B) scores; and

ES is the assessment score for the condition.

\subsection{Study Area}

The north central Nigeria (Figure 2) consists of six states, namely: Benue, Kogi, Kwara, Nassarawa, Niger, Plateau, and the Federal Capital Territory (FCT). The region has a population of 20.3 million (2006 estimate) and the main economic activity is agriculture. Other activities include fishing, mining, and businesses. The most significant feature of the region in terms of water resources is the Niger Basin with an area of 584,193 $\mathrm{km}^{2}$ within 


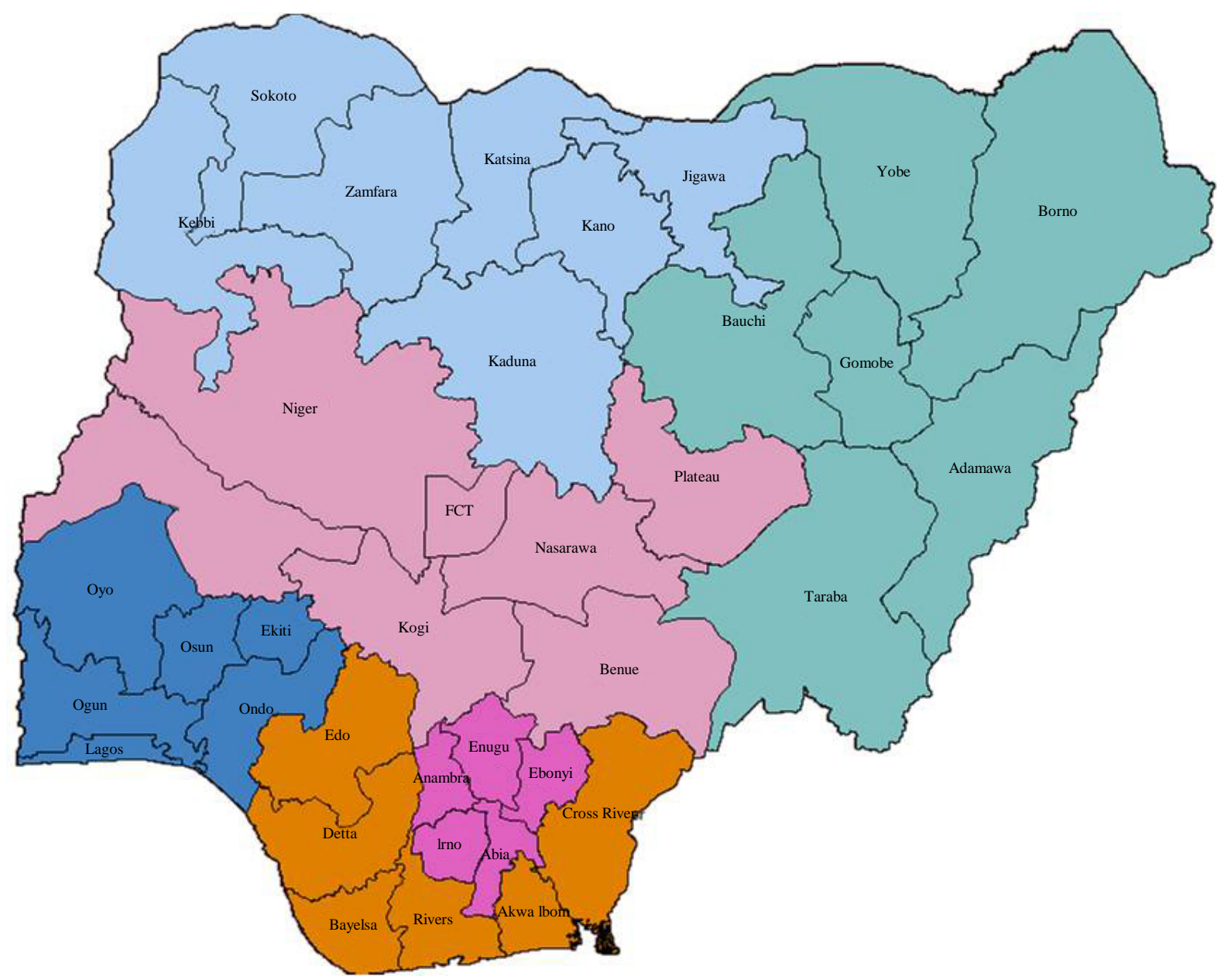

Figure 2. Map of Nigeria showing the north central zone. $\quad$ L: North Central Nigeria

the country which is 63 percent of the total area of the country and covers a large area in north central region [9]. There has been an increase in the social and economic activities in this region in the past decades due to the location of the FCT which has continue to attract people thus adding pressure to the existing water infrastructure.

\subsection{Rapid Impact Assessment Matrix (RIAM)}

The rapid impact assessment matrix (RIAM) is one of the frontiers tool commonly employed in the study of environmental impact assessment (EIA). RIAM uses a structured matrix to allow for judgments both subjective and those based on quantitative data to be made on a like-by-like basis, and provides a transparent and permanent record of the judgments made [8]. The concept of RIAM was developed to improve the existing key shortcomings of the EIA methods. According to Kankam-Yeboah et al., [7], the simple and structured form of RIAM allows reanalysis and in-depth analysis of selected components in a rapid and accurate manner. This flexibility makes the method powerful tool for both executing and evaluating impact assessments. RIAM is based on the knowledge that certain specific criteria are common to all impact assessments and by scaling these criteria, it becomes possible to record the values of the assessments made. It was adopted for study to prioritize the water resources management to know which problems require the most urgent attention and mitigation measures particularly in the eyes of stakeholders who at the receiving end of policy implementation.

\subsubsection{Water Resources Management Problems}

The following eleven problems were identified by the stakeholders to be most severe in the north central region in order of severity. 
1) Bad governance.

2) Inadequate data for planning.

3) Misappropriation of available funds.

4) Pollution.

5) Poor data collection and banking.

6) Limited groundwater in some areas.

7) Contaminated source of water.

8) Flood.

9) Indiscriminate groundwater exploitation.

10) Inadequate funds for further agricultural, hydroelectric, navigational and industrial development.

11) Lack of operational sustainability.

Each of these problems was then evaluated by the stakeholders by assigning scores in Table 2. The RIAM model (Equations (1)-(3)) was then applied to get the Assessment Scores (ES) for each component. The average of the ES calculated for each problem was taken along with the corresponding Range Band selected in Table 3. The scoring was done by experts from water related disciplines. They have acquired vast experiences over the years working in water related discipline. They also have firsthand information on the efficient management of water resources in the region which qualifies them for the scoring in this technique.

\subsubsection{Impact Indicators}

This study adopted the following impact indicators which are among the most relevant and widely used indicators for the assessment and analysis of water management problems [7] [10]:

1) Environmental quality.

2) Degree of tolerance to the public.

\section{Table 2. Assessment criteria.}

\begin{tabular}{|c|c|c|}
\hline Criteria & Scale & Description \\
\hline \multirow[t]{5}{*}{ A1: Importance of condition } & 4 & Important to national/international interest \\
\hline & 3 & Important to regional/national interest \\
\hline & 2 & $\begin{array}{l}\text { Important to areas immediately outside the } \\
\text { local condition }\end{array}$ \\
\hline & 1 & Important only to local condition \\
\hline & 0 & No importance \\
\hline \multirow[t]{7}{*}{ A2: Magnitude of change/effect } & +3 & Major positive benefits \\
\hline & +2 & Significant improvement in status quo \\
\hline & +1 & Improvement in status quo \\
\hline & 0 & No change/status quo \\
\hline & -1 & Negative change in status quo \\
\hline & -2 & Significant negative change \\
\hline & -3 & major change \\
\hline \multirow[t]{6}{*}{ B1: Permanence } & 1 & No change/not applicable \\
\hline & 2 & Temporary \\
\hline & 3 & Permanent \\
\hline & 1 & No change/not applicable \\
\hline & 2 & Reversible \\
\hline & 3 & Irreversible \\
\hline \multirow[t]{3}{*}{ B3: Cumulative } & 1 & No change/not applicable \\
\hline & 2 & Non-cumulative/single \\
\hline & 3 & Cumulative/synergistic \\
\hline
\end{tabular}

Source: [8]. 
Table 3. Conversion of environmental scores to range bands.

\begin{tabular}{ccc}
\hline Environmental score & Range bands & Description of range bands \\
+72 to +108 & $+\mathrm{E}$ & Major positive change/impacts \\
+36 to +71 & $+\mathrm{D}$ & Significant positive change/impacts \\
+19 to +35 & $+\mathrm{C}$ & Moderately positive change/impacts \\
+10 to +18 & $+\mathrm{B}$ & Positive change/impacts \\
+1 to +9 & $+\mathrm{A}$ & Slightly positive change/impacts \\
0 & $\mathrm{~N}$ & No change/status quo/not applicable \\
-1 to -9 & $-\mathrm{A}$ & Slightly negative change/impacts \\
-10 to -18 & $-\mathrm{B}$ & Negative change/impacts \\
-19 to -35 & $-\mathrm{C}$ & Moderately negative change/impacts \\
-36 to -71 & $-\mathrm{D}$ & Significantly negative change/impacts \\
-72 to -108 & $-\mathrm{E}$ & Major negative change/impacts \\
\hline
\end{tabular}

Source: [8].

3) Political and legal feasibility.

4) Equity and gender issue.

5) Economic growth.

6) Technical feasibility.

7) Health care delivery.

8) Safe water supply and consumption.

9) Biodiversity/ecosystem.

10) Water quality enhancement.

11) Cost of option.

12) Energy supply.

13) Security and reliability of water supply.

These impact indicators were subsequently grouped into four components (Table 4).

\section{Result and Discussions}

The histogram of the RIAM result provides a comparative picture of the negative impacts of all the problems assessed shown Figures 3-13. The Range Bands are represented on the horizontal scale of the histograms. N stands for neutral and the negative alphabets shows the negative impacts of the component. The vertical scale indicates the scores. PC represents physical/chemical component, BE represents biological/ecological component, SC represents sociological/cultural component and EO represents economical/operational component.

The most severe problem is that with the highest number of negative scores. In this study "Inadequate funds for further agricultural, hydroelectric, navigation and industrial development" recorded the score of 14 under $(-\mathrm{D})$ which is the maximum score obtained for all the criteria in the component and 3 under $(-\mathrm{C})$. This is followed closely by "Poor data collection and banking" with a score of 13 under $(-D)$ and 4 under $(-C)$. However," Indiscriminate groundwater exploitation", "Bad governance" and "inadequate data for planning" tie with the score of 11 under $(-D)$ and 6 under $(-C)$. The implication is that the three problems are considered to have the same level of urgency as regards the intervention measures they require. "Flood" is the next with the score of 11 recorded under $(-D), 5$ under $(-C)$ and 1 under $(-B)$ which is followed closely by "Misappropriation of funds" with the score 10 under $(-D), 6$ under $(-C)$ and 1 under $(-B)$. "Pollution" records 9 under $(-D)$ and 8 under $(-\mathrm{C})$; "Contaminated sources of water" records 9 under $(-\mathrm{D}), 6$ under $(-\mathrm{C})$ and 2 under $(-\mathrm{B})$; "Lack of operational sustainability" records 8 under $(-D)$ and 9 under $(-C)$ and the problem requiring the least attention on the list is "Limited groundwater in some areas" with the score 7 recorded under $(-D)$ and 10 under $(-C)$.

The overall representation of all components is shown in Figure 14. The Figure indicates a total of 114 scores registered under the $-\mathrm{D}$ (significantly negative impacts), 69 scores registered for $-\mathrm{C}$ (moderately negative impacts) and a score of 4 for $-\mathrm{B}$ (negative impacts). A major characteristic of the RIAM model is that the most significant impact $(-\mathrm{D})$ is considered as the impact that should receive the most urgent attention in terms of 
Table 4. Components and description.

\begin{tabular}{|c|c|c|}
\hline S/No. & Components & Description \\
\hline 1. & Physical/chemical & $\begin{array}{l}\text { This group covers all physical and } \\
\text { chemical aspects of the water resources } \\
\text { management, including non-renewable } \\
\text { natural resources and degradation of the } \\
\text { physical environment through pollution. }\end{array}$ \\
\hline 2. & Biological/ecological & $\begin{array}{l}\text { This group includes all biological aspects } \\
\text { of the water resources covers management, } \\
\text { including renewable natural resources, } \\
\text { conservation of biodiversity, species } \\
\text { interaction and pollution of biosphere. }\end{array}$ \\
\hline 3. & Sociological/cultural & $\begin{array}{l}\text { This group encompasses human aspects of } \\
\text { the water resources management, including } \\
\text { social issues affecting individuals and } \\
\text { community; together with cultural aspects } \\
\text { including conservation of heritage and } \\
\text { human development. }\end{array}$ \\
\hline 4. & Economic/operation & $\begin{array}{l}\text { This group is used to qualitatively identify } \\
\text { the economic consequences of change in } \\
\text { water resources management, both } \\
\text { temporary and permanent. }\end{array}$ \\
\hline
\end{tabular}

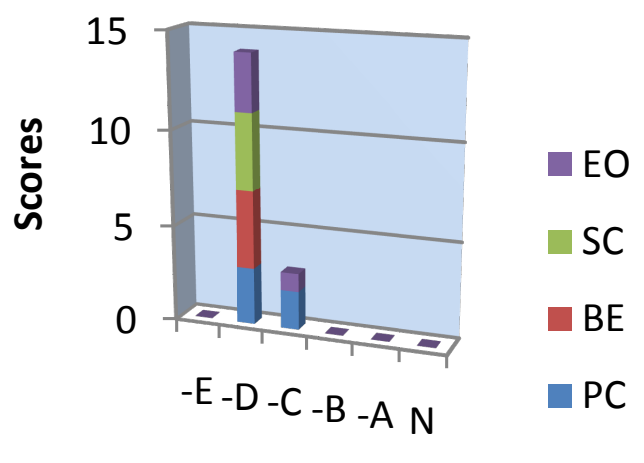

\section{Range Band}

Figure 3. RIAM output for "inadequate, funds for further agricultural, hydro-electric, navigational and industrial development”.

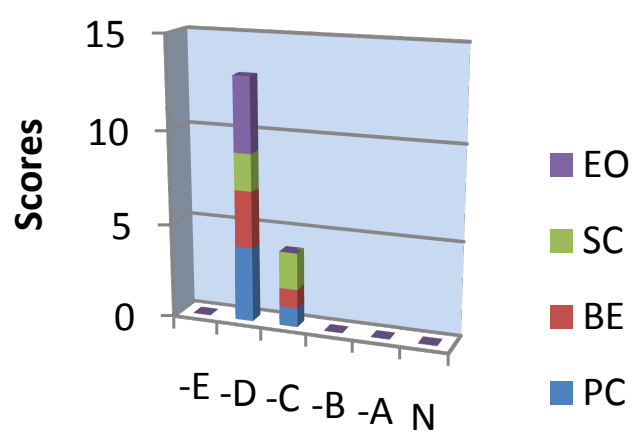

Range Band

Figure 4. RIAM output for "poor data collection and Banking”. 


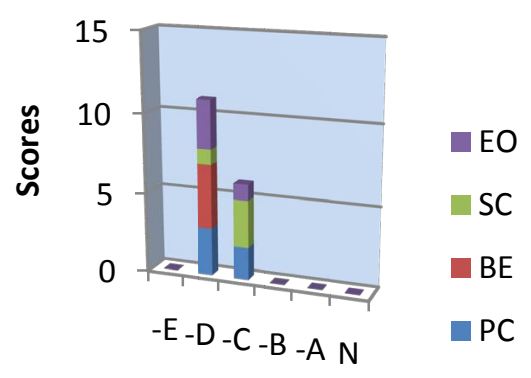

Range Band

Figure 5. RIAM output for "indiscriminate groundwater exploitation”.

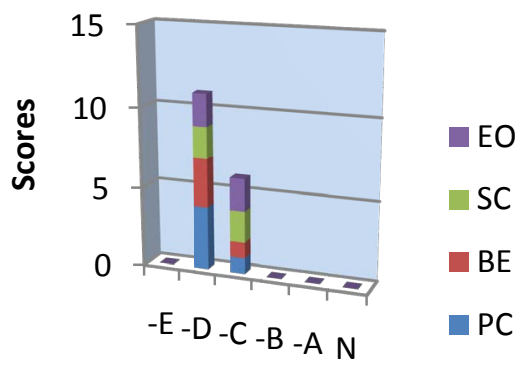

Range Band

Figure 6. RIAM output for "bad governance”.

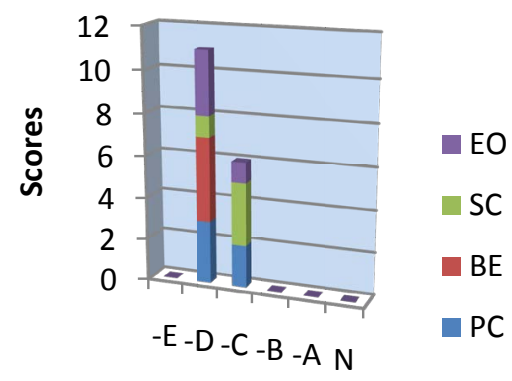

Range Band

Figure 7. RIAM output for "inadequate data for planning”.

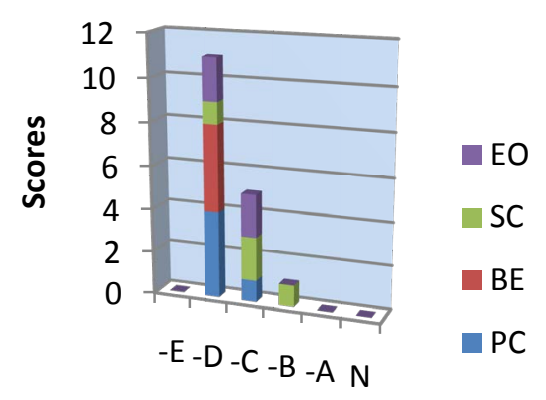

Range Band

Figure 8. RIAM output for "flood". 


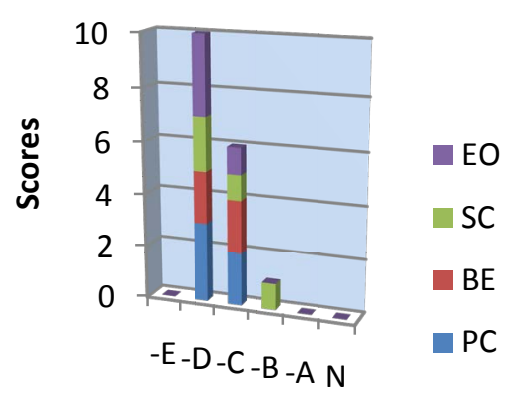

Range Band

Figure 9. RIAM output for "misappropriation of available funds”.

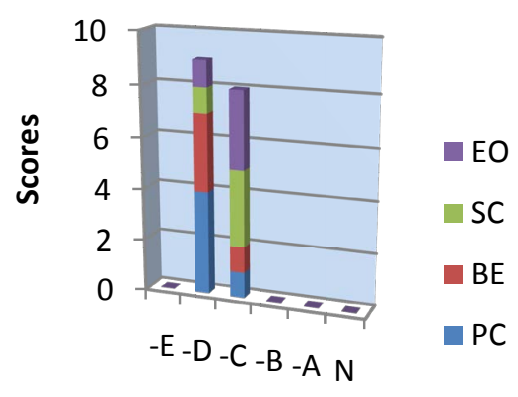

Range Band

Figure 10. RIAM output for “pollution”.

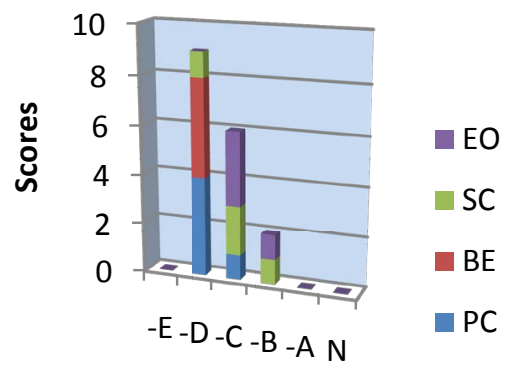

Range Band

Figure 11. RIAM output for "Contaminated sources of water".

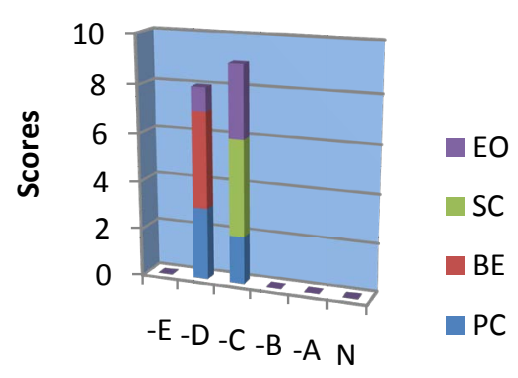

Range Band

Figure 12. RIAM output for "lack of operational sustainability”. 


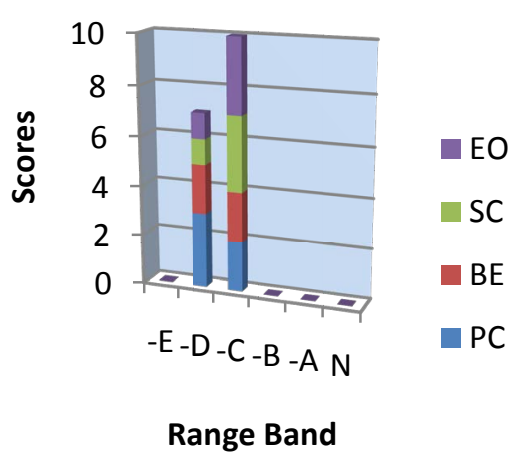

Figure 13. RIAM output for "limited groundwater in some areas”.

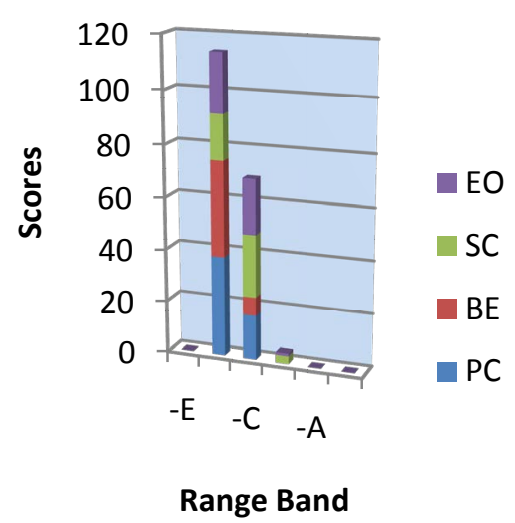

Figure 14. Overall representation of the RIAM output.

mitigation and intervention measures before the next significant impact $(-\mathrm{C})$. Consequently, a problem registering a single $-D$ takes precedence over a problem which registers say twice or more $-C$ in terms of which of them requires the most urgent attention and intervention. The significantly negative impacts having registered the highest scores indicate that majority of the evaluated problems are considered to require urgent attention and mitigation measures. However, the order in which they are to be selected for quick intervention is provided by the RIAM in the priority list in Table 5.

The result of the prioritization of water resources management problems using the RIAM technique is summarized in Table 5. "Inadequate funds for further agricultural, hydroelectric, navigation and industrial development" recorded the most negative impacts with a score of -14 registered under $(-D)$ and -3 under $(-C)$. This result supported the work of [11]-[13] in their various study of application of severity index in matrix order (SIMO) model in empirical ranking where "insufficient funding for infrastructures" was listed as one of the critical factors to infrastructural service delivery failures in the Nigeria.

The results obtained from RIAM tool was compared with the stakeholders' conventional ranking of the different categories of water resources management problems and also that of individual ranking of problems. While individual problem ranking was different from that of RIAM, they both agree with the ranking of categories of water resources problems. This could be as a result of the usage of questionnaire instead of an organized workshop which facilitates insightful thoughts and inclusive discourse. The questionnaires completion at different periods with extended interval of time easily results in discontinuity in their critical thinking.

\section{Conclusions}

The RIAM technique has been successfully applied to the north central water resources management. It has made a key contribution to the prioritization of water resources management by providing insight into the most urgent problem that requires immediate intervention for the zone at least according to policy implementers. 
Table 5. Result of the prioritization of the water resources management problems.

\begin{tabular}{|c|c|c|c|c|c|c|c|}
\hline No. & Water resources management problems & $-\mathbf{E}$ & $-\mathbf{D}$ & $-\mathrm{C}$ & $-\mathbf{B}$ & $-\mathbf{A}$ & $\mathbf{N}$ \\
\hline 1 & $\begin{array}{l}\text { Inadequate funds for further agric. Hydroelectric, } \\
\text { navigation and industrial development }\end{array}$ & & 14 & 3 & & & \\
\hline 2 & Poor data collection and banking & & 13 & 4 & & & \\
\hline 3 & Indiscriminate groundwater exploitation & & 11 & 6 & & & \\
\hline 4 & Bad governance & & 11 & 6 & & & \\
\hline 5 & Inadequate data for planning & & 11 & 6 & & & \\
\hline 6 & Flood & & 11 & 5 & 1 & & \\
\hline 7 & Misappropriation of the available funds & & 10 & 6 & 1 & & \\
\hline 8 & Pollution & & 9 & 8 & & & \\
\hline 9 & Contaminated sources of water & & 9 & 6 & 2 & & \\
\hline 10 & Lack of operational sustainability & & 8 & 9 & & & \\
\hline \multirow[t]{2}{*}{11} & Limited groundwater in some areas & & 7 & 10 & & & \\
\hline & Total & & 114 & 69 & 4 & & \\
\hline
\end{tabular}

Eleven problems were analyzed by RIAM technique based on the physical/chemical, biological/ecological, social/cultural and economic/operational factors using several impact indicators. The RIAM identified 1) "inadequate funds for further agricultural, hydroelectric, navigation and industrial development" as the number 1 challenge demanding attention and 2) "poor data collection and banking" as the number 2. The RIAM obtained result constitutes a vital and insightful guide for decision makers in articulating effective sustainable policy and reforms in the management of the region's water resources.

It is recommended that the key stakeholders (FMWR and LNRDA) set in motion a strategy to address the challenges that will have widespread citizenry appreciation. This can be done through collaborative and interdisciplinary research using this study as baseline. It is also imperative to extend this application to other geopolitical zone of the country.

\section{References}

[1] Federal Government of Nigeria (2011) Executive Summary of the Nigeria Water Sector Roadmap. Federal Ministry of Water Resources, Abuja.

[2] Federal Ministry of Water Resources (2014) http://www.waterresources.gov.ng/about/core-functions

[3] Ali, K.A. (2012) Development of Water Supply Infrastructure in Nigeria: Challenges and Prospects. Nigeria Society of Engineers October Lecture, Abuja.

[4] Okeola, O.G. and Sule, B.F. (2011) Evaluation of Management Alternatives for Urban Water Supply System Using Multicriteria Decision Analysis. Journal of King Saud University_Engineering Science, 24, 19-24. http://dx.doi.org/10.1016/j.jksues.2011.07.004

[5] Schardong, A. and Simonovic, S.P. (2011) Multi-Objective Evolutionary Algorithms of Water Resources Management. Water Resources Research Report. Report No. 078, Department of Civil and Environmental Engineering, University of Western Ontario, Canada.

[6] Yilmaz, B. and Harmanacioglu (2010) Multi-Criteria Decision Making for Water Resources Management: A Case Study of Gediz River Basin, Turkey. Water SA, 36, 563-576. http://dx.doi.org/10.4314/wsa.v36i5.61990

[7] Kankam-Yeboah, K., Asare, E.B., Gyau-Boakye, P. and Nishigaki, M. (2005) Rapid Impact Assessment Matrix (RIAM) - An Analytical Tool in the Prioritization of Water Resources Management Problems in Ghana. Journal of the Faculty of Environmental Science and Technology, Okayama University, 10, 75-81.

[8] Pastakia, C.M.R. and Jensen, A. (1998) The Rapid Impact Assessment Matrix (RIAM) for Environmental Impact Assessment. Environmental Impact Assessment Review, 18, 461-462. http://dx.doi.org/10.1016/S0195-9255(98)00018-3

[9] Food and Agriculture Organization of the United Nations (2005) AQUASTAT_FAO's Information System on Water and Agriculture. http://www.fao.org/waicent/faoinfo/agricult/agl/aglw/aquastat/countries/nigeria/index.stm

[10] Hajkowicz, S. and Collins, K. (2007) A Review of Multiple Criteria Analysis for Water Resources Planning and Management. Water Resources Management, 21, 1553-1566. http://dx.doi.org/10.1007/s11269-006-9112-5 
[11] Okeola, O.G. and Salami, A.W. (2012) A Pragmatic Approach to the Nigeria’s Engineering Infrastructure Dilemma. Epistemics in Science, Engineering and Technology, 2, 55-61.

[12] Adenikinju, A. (2005) Analysis of the Cost of Infrastructure Failures in Developing Economy: The Case Study of Electricity Sector in Nigeria. AERC Research Paper 148, African Economic Research Consortium, Nairobi.

[13] Omoregie, A., Ebohon, O.J. and Radford, D. (2011) Modeling in Ranking Procedures: A Case Study: Infrastructure Failure in Nigeria. School of Architecture, De Montfort University, Leceister.

http://www.irbdirect.de/daten/iconda/cib10618.pdf 